\title{
Targeting Sensory Axon Regeneration in Adult Spinal Cord
}

\author{
Xiao-Qing Tang, Paula Heron, Charles Mashburn, and George M. Smith \\ Department of Physiology, Spinal Cord and Brain Injury Research Center, University of Kentucky Chandler Medical Center, Lexington, Kentucky 40536- \\ 0298
}

Extensive regeneration of sensory axons into the spinal cord can be achieved experimentally after dorsal root injury, but no effort has been made to target regenerating axons and restore a normal lamina-specific projection pattern. Ectopic axon growth is potentially associated with functional disorders such as chronic pain and autonomic dysreflexia. This study was designed to target regenerating axons to normal synaptic locations in the spinal cord by combining positive and negative guidance molecules. Previously, we observed that, after dorsal rhizotomy, overexpression of NGF leads to robust regeneration and sprouting of calcitonin gene-related peptide (CGRP)-positive nociceptive axons throughout dorsal horn and ventral horns. To restrict these axons within superficial laminas, adenovirus expressing semaphorin $3 \mathrm{~A}$ was injected into the ventral spinal cord $3 \mathrm{~d}$ after NGF virus injection. Semaphorin $3 \mathrm{~A}$ expression was observed in deep dorsal and ventral cord regions and limited axon growth to laminas I and II, shaping axonal regeneration toward the normal distribution pattern. NGF and semaphorin $3 \mathrm{~A}$ treatment also targeted the regeneration of substance P-positive nociceptive axons but had no effect on injured isolectin B4-binding nociceptive axons. Axon regeneration led to functional restoration of nociception in both NGF- and NGF/semaphorin 3A-treated rats. Although no significant difference in behavior was found between these two groups, confocal microscopy illustrated ectopic synaptic formations in deeper laminas in NGF/green fluorescent protein-treated rats. The results suggested that antagonistic guidance cues can be used to induce and refine regeneration within the CNS, which is important for longterm, optimal functional recovery.

Key words: semaphorin 3A; nerve growth factor; primary nociceptive axons; regeneration; axon guidance; lamina specific

\section{Introduction}

Paramount to functional recovery is reestablishment of synaptic connections to the most appropriate target region. In many regions of the CNS, laminar specificity is an important determinant of synaptic specificity (Sanes and Yamagata, 1999). Reestablishment of laminar specificity should allow higher-order plasticity to modify circuits and correct slight targeting errors. With this in mind, can regenerating axons in the adult be targeted to laminarspecific regions and will this increase synaptic density within that lamina? Studies showed that receptors of some developmentally important guidance cues continue to operate in adulthood; thus, it may be possible to exogenously provide essential guidance support after adult CNS injury. Conversely, difficulty has remained for introducing guidance molecules in a temporal and spatial manner conducive to restoring the exquisite organization of specific neuronal pathways. To this end, we incorporated a developmental repulsive guidance mechanism (Kolodkin, 1996) into our regeneration strategy (Romero et al., 2001; Tang et al., 2004a) to aid the patterning of connections during sensory axon regeneration. The refined strategy uses both positive and negative cues to

Received 0ct. 24, 2006; accepted April 25, 2007.

This work was supported by National Institute of Neurological Disorders and Stroke Grant NS 38126 and the Kentucky Spinal Cord and Head Injury Trust. We thank Aileen P. Lim and Jun Yang for technical assistance and image quantification.

Correspondence should be addressed to Dr. George M. Smith, Department of Physiology, Spinal Cord and Brain Injury Research Center, University of Kentucky Chandler Medical Center, Lexington, KY 40536-0298. E-mail: gmsmith@uky.edu.

DOI:10.1523/JNEUROSCI.1442-07.2007

Copyright $\odot 2007$ Society for Neuroscience $\quad$ 0270-6474/07/276068-11\$15.00/0 generate a dorsal gradient to induce axon regeneration that diminishes ventrally into a chemorepulsive gradient to limit regeneration to the upper dorsal lamina of the spinal cord.

Developmental growth and guidance of sensory axons through the dorsal roots and into the spinal cord has been studied extensively. These axons enter the spinal cord from the root and terminate at distinct laminas in spinal cord gray matter. Different subtypes of sensory axons show prominent lamina-specific connectivity: calcitonin gene-related peptide (CGRP)- and substance $\mathrm{P}(\mathrm{SP})$-positive $(+)$ nociceptors restrict their terminals to lamina I and the outer aspect of lamina II (IIo), isolectin B4 (IB4)binding nociceptors to the inner aspect of lamina II (IIi), and TrkC-positive proprioceptors to Clark's column and the ventral horn. After dorsal root injury in adult animals, sensory axons regenerate within the dorsal root but will stop abruptly after contact with the surface of the spinal cord. Features of the dorsal root entry zone (DREZ) (a specialized transitional zone between the spinal cord and the dorsal root) generate a nonpermissive barrier for regenerating sensory axons analogous to regenerative obstacles present after other CNS injuries (Pindzola et al., 1993; Aldskogius and Kozlova, 2002; Priestley et al., 2002). These features make dorsal root injury a suitable and simplified model to study CNS regeneration and restoration of specific projection patterns. Previous studies show that combined zymosan and chondroitinase $A B C$ treatment or the application of neurotrophins facilitates functional regeneration of sensory axon through the DREZ and into the spinal cord (Ramer et al., 2000; Romero et al., 2001; Steinmetz et al., 2005). The best regeneration has been observed with nociceptive C-fiber axons (CGRP- and SP-containing) in 
the presence of nerve growth factor (NGF). Notably, these regenerating C-fibers fail to terminate at their normal targets (laminas I and IIo) and regenerate throughout the entire dorsal horn (Romero et al., 2001; Tang et al., 2004a). Because adult C-fibers respond to semaphorin $3 \mathrm{~A}$ (Sema3A), which is thought to prevent their growth into deeper dorsal laminas during development, selective coexpression of NGF and sema3A was used to target a lamina-restricted connection pattern for injured CGRP ${ }^{+}$ and $\mathrm{SP}^{+}$nociceptive afferents.

\section{Materials and Methods}

Animals. Fifty-four adult (250-350 g) female Sprague Dawley rats (Harlan Sprague Dawley, Indianapolis, IN) were used in this study. All surgical procedures and animal maintenance complied with the National Institutes of Health guidelines regarding the care and use of experimental animals and were approved by the Institutional Animal Care and Research Advisory Committee.

Adenoviral vectors. Replication-defective recombinant adenoviruses (Ad) expressing nerve growth factor (NGF/Ad), green fluorescent protein (GFP/Ad, control virus) and semaphorin 3A (Sema3A/Ad) were constructed as described previously (Romero et al., 2000; Tang et al., 2004a). In addition to standard deletions in E1 and E3 coding regions, all viruses also encoded the $t s 125$ mutation in the E2a, DNA binding protein, to further reduce potential toxicity after administration in vivo (Romero and Smith, 1998). All plaque-purified adenoviruses were examined for replication-competent adenoviruses via PCR. Viruses were then amplified and purified by double cesium chloride gradient ultracentrifugation. The physical number of viral particles was determined by optical absorbency. The number of infectious particles was estimated using Adeno-X Rapid titer kit (Clontech, Palo Alto, CA) or directly counting green fluorescent cells $48 \mathrm{~h}$ after transduction of human embryonic kidney 293 cells. The quality of these viruses was determined by examining the ratio of infectious to total (live and dead) number of virus, which was $\sim 1: 50$ pfu to total virus particles.

Surgical procedures. Deeply anesthetized animals [ketamine $(67 \mathrm{mg} / \mathrm{kg}$, i.p.)/xylazine $(6.7 \mathrm{mg} / \mathrm{kg}$, i.p.)] underwent a hemilaminectomy at the L1-L2 vertebral segments to expose the lumbar dorsal roots. With the use of \#5 Dummond forceps, triple-crush lesions of $10 \mathrm{~s}$ each were inflicted at two sites separated by $3 \mathrm{~mm}$ along the L4, L5 afferents at $\sim 5-8 \mathrm{~mm}$ from the DREZ. The dorsal roots immediately rostral (L3) and caudal (L6) to the injured site were double crushed and tightly ligated to create a zone of dennervation immediately rostral and caudal L4/L5. All lesions were performed unilaterally on the right side.

Two weeks after dorsal root injury, all animals received a second hemilaminectomy at the T13-L1 vertebral segments to expose the lumbar spinal cord. For injections of GFP/Ad, NGF+GFP/Ad, or $\mathrm{NGF}+\mathrm{Sema} 3 \mathrm{~A} / \mathrm{Ad}$, the needle was inserted through the intact dura and into the spinal cord along the L4, L5 DREZ. For the rats receiving a combination of two virus treatments, the second virus (GFP or Sema3A/ Ad) was given $3 \mathrm{~d}$ after NGF/Ad treatment. For these animals, after NGF/Ad administration, the spinal cord above the dura was covered with a small piece of stretched Parafilm and a piece of $50 \%$ dextran sulfatesoaked Gelfoam to reduce scar formation (Wujek et al., 1991) and facilitate injections of the second virus. Each virus administration consists of eight injections $(0.3 \mu \mathrm{l} / \mathrm{each}, 0.5 \mathrm{~mm}$ apart, $0.6 \mathrm{~mm}$ deep for NGF/Ad and $1.2 \mathrm{~mm}$ deep for GFP or Sema3A/Ad) of adenoviral vectors (NGF/ Ad, $5 \times 10^{4} \mathrm{pfu} / \mu \mathrm{l}$; GFP or Sema3A/Ad, $\left.1.25 \times 10^{6} \mathrm{pfu} / \mu \mathrm{l}\right)$ along the DREZ. All injections were performed using a beveled glass micropipette pulled to an external diameter of between 30 and $50 \mu \mathrm{m}$. A total of $300 \mathrm{nl}$ were injected at each site using a nano-injector (World Precision Instruments, Sarasota, FL) at a precise depth from the spinal cord dorsal surface using the coordinates on a M3301 fine micromanipulator (Narishige via World Precision Instruments). Viral doses were determined from previous studies and pilot experiments. Before and the next day after each virus administration, rats received $100 \mu \mathrm{g}$ intraperitoneally of a 1:1 combined solution of CD-4 (W3/25) and CD-45 (MRC OX-22) antisera to transiently suppress the immune response.

For relesion experiments, right L4 and L5 dorsal roots were reexposed
4 weeks after adenovirus injections ( 6 weeks after injury). The roots were relesioned by transection, and the proximal stump was ligated to prevent any axonal regeneration.

Western blots. One week after injections, the L4/L5 segment of shaminjured rats injected with NGF, GFP, or Sema3a Adt were processed for Western blot analysis ( $n=2$ per group) as described previously (Tang et al., 2004b). Briefly, a $4 \mathrm{~mm}$ segment of the dorsal spinal cord containing the injected region was dissected and immediately frozen. The tissue was then homogenized manually with a Dounce in $200 \mu \mathrm{l}$ of $1 \%$ SDS in Tris-EDTA buffer with proteinase inhibitors $(10 \mu \mathrm{g} / \mathrm{ml}$ aprotinin, 1 $\mu \mathrm{g} / \mathrm{ml}$ leupeptin, and $1 \mathrm{~mm}$ PMSF) and sonicated using a Branson sonifier 450 (VWR Scientific, West Chester, PA). After centrifuging at 14,000 rpm, supernatant was assayed for protein concentration using a BCA kit (Pierce, Rockford, IL) and diluted with $3 \times$ Laemmli's buffer, and $50 \mu \mathrm{g}$ of protein was loaded for each sample. After running the sample in $14 \%$ (for NGF) or 7.5\% (for Sema3A) SDS-polyacrylamide gel, proteins were transferred to nitrocellulose membranes. Membranes were blocked using Odyssey (LI-COR Biosciences, Lincoln, NE) blocking buffer. NGF was identified by rabbit anti-NGF antibody (1:500; Accurate Chemicals, Westbury, NY), and adenovirus-mediated Sema3A expression was detected by mouse anti-myc (9E10, 1:2000; Upstate, Charlottesville, VA), and semaphorin 3A was detected using a rabbit anti-Sema3A (SP1221, 1:500; ECM Bioscience, Versailles, KY). After a $2 \mathrm{~h}$ incubation in primary antibody, the membranes were washed five times for $10 \mathrm{~min}$ in Trisbuffered saline with $0.1 \%$ Tween 20 and incubated in goat anti-rabbit (for NGF and Sema3A) or mouse (for c-myc) IgG (1:7500; Invitrogen, Carlsbad, CA) conjugated with AlexaFluor 680 for $1 \mathrm{~h}$. Membranes were washed as above, and images were captured using an Odyssey infrared imaging system (LI-COR Biosciences) at $700 \mathrm{~nm}$.

Retrograde tracing. To evaluate neuronal populations regenerating into the dorsal horn, two fluorescent tracers were used for the retrograde tracing experiments. All tracer injections were made on the right side, through a beveled glass micropipette connected to a Nanoliter injector. Immediately after L4, L5 double-crush injury, $4 \mu \mathrm{l}$ of $5 \%$ fluorogold (FG) (in 20\% DMSO, Biotium, Hayward, CA) was injected into the crush site to label all lesioned neurons in corresponding DRGs. The animals then received injections of adenoviral vectors 2 weeks after injury, as described above. Three weeks after virus injections, the L4, L5 spinal cord was reexposed, and eight injections $(0.15 \mu \mathrm{l} /$ each, $0.5 \mathrm{~mm}$ apart, $0.7 \mathrm{~mm}$ deep) of 5\% dextran-Texas Red (TR) (in 20\% DMSO; Invitrogen, Carlsbad, CA) were made into the cord. For all dye injections, the needle was inserted into the dorsal midline at a $30^{\circ}$ angle to avoid dye injection into the DREZ. The wound was closed, and the rat was allowed to survive for 1 week before it was killed. All spinal cord sections were examined for dye injection to verify accuracy of injection into the upper dorsal horn (supplemental Fig. 1, available at www.jneurosci.org as supplemental material).

Histology. Four or 6 weeks (for the relesion experiment) after adenovirus injections, animals were anesthetized using sodium pentobarbital (Nembutal, $90 \mathrm{mg} / \mathrm{kg}$ ), perfused transcardially with $0.9 \%$ saline, followed by $4 \%$ paraformaldehyde in $0.1 \mathrm{~m}$ phosphate buffer, $\mathrm{pH}$ 7.5. Lumbar spinal cord and DRGs were taken out and incubated in the same fixative for $\sim 24 \mathrm{~h}$. The tissue was then cryoprotected with $30 \%$ sucrose in $0.1 \mathrm{M}$ phosphate buffer at $4^{\circ} \mathrm{C}$ for another $2 \mathrm{~d}$. Thirty-micrometer slide (for DRGs) or floating (for spinal cord) sections were cut on a cryostat. All fluorescent (expressing GFP) tissue sections was handled and stored in the dark.

For immunoperoxidase staining, spinal cord sections were incubated with polyclonal antiserum against rat CGRP (1:20,000; Sigma, St. Louis, $\mathrm{MO})$. Visualization was achieved by incubating tissue in biotinylated secondary antibodies followed by the Vectastain Elite $\mathrm{ABC}$ reagents (Vector Laboratories, Burlingame, CA), and developed using the peroxidase substrate, 3,3-diaminobenzidine to generate a brown color.

For single- or double-fluorescence staining, spinal cord or DRG sections were incubated in anti-CGRP (1:500 to 1:1000), substance P (1:500; Research Biochemicals, Natick, MA), myc (9E10, ascites, 1:100; American Type Culture Collection, Manassas, VA), synaptophysin (1:400; Sigma), or a biotinylated IB4 solution (1:1000; Sigma). For double staining, two antibodies were added to the incubation simultaneously. Red 
and green fluorescence labeling were achieved by additional incubation in species-specific Texas Red- and FITC-conjugated secondary antibodies, respectively (Jackson ImmunoResearch, West Grove, PA). Blue fluorescence labeling was achieved by direct incubation in 7-amino-4methylcoumarin-3-acetic acid-conjugated streptavidin (for IB4 staining) or incubation in a biotinylated secondary antibody, followed by AMPA-streptavidin incubation (Jackson ImmunoResearch). After staining, sections were coverslipped with $5 \%$ propyl-gallate in glycerol for fluorescence microscopy.

Image analysis. To quantify axon growth in different laminas of the spinal cord, three sections within L4, L5 spinal cord were randomly selected for each animal. Outlines of laminas I to VI were drawn on a representative spinal cord image (see Fig. 2A). Using MetaMorph Imaging System 5.0 (Universal Imaging, West Chester, PA), the outlines were set as a template and applied to appropriate locations in different spinal cord images by a technician blinded to the experimental conditions. CGRP axon-occupying area was quantified within the outline of each lamina using a macro that applied a standardized optical density threshold to each image and measured the area of staining equal to or greater than threshold. The program was calibrated for automatic conversion of area measurements into micrometers.

To count the number of fluorescent-labeled neurons in DRGs, the tissue was cut at $30 \mu \mathrm{m}$ thickness in complete section series through the DRG. Every third section (10 per DRG) was used for counting labeled DRG neurons. The sections were observed under $10 \times$ objective of an E-800 epifluorescent microscope (Nikon, Tokyo, Japan). Texas Redlabeled neurons were visualized using filter for Texas Red (excitation wavelength, $540-580 \mathrm{~nm}$ ), and fluorogold-labeled neurons were visualized with UV-2A filter (excitation wavelength, 330-380 nm). Digital images of randomly selected areas from sections were taken using MetaMorph Imaging software. Fluorogold-labeled, Texas Red-labeled, and colabeled neurons with clear cell bodies and visible nuclei were counted manually from the pictures, and the number was compared between different groups. All image analysis was done under blinded conditions.

Behavioral analysis. The latency of paw withdrawal from a radiant heat source was used to measure the response time to noxious thermal stimuli, as described previously (Hargreaves et al., 1988). All animals were tested before the surgery to establish baseline latencies, after which, testing was performed once every week. Briefly, we placed the rats into an inverted clear plastic chamber on a glass floor. After a 5 min acclimation period, the plantar surface of the hindpaw was exposed to a beam of calibrated radiant heat applied through the glass floor. Paw withdrawal latency (PWL) was detected automatically by a photocell and taken as a behavioral index of the nociceptive threshold. Therefore, a score that was increased significantly over baseline represented analgesia (antinociception). A $22 \mathrm{~s}$ maximum was used to ensure that no tissue damage occurred to the paw. Individuals conducting these experiments were blinded to the treatment. PWL readings were always taken in duplicate at $\sim 10$ min intervals.

Confocal microscope analysis. Single optical sections through the dorsal horn were obtained with a Leica (Nussloch, Germany) TCS SP laser scanning inverted confocal microscope equipped with a $100 \times$ oil objective, argon/krypton, helium/neon, and multiphoton lasers. Fluorescent images were acquired in the near red (tetramethylrhodamine isothiocyanate, $600-680 \mathrm{~nm})$ and UV $(410-470 \mathrm{~nm})$ range. Sequential scanning was performed with the resolution set to $1024 \times 1024$ pixels, and single optical sections $\sim 1 \mu \mathrm{m}$ thick were captured. All focal planes containing labeled CGRP fibers and synaptophysin puncta were stacked. The stacked sections obtained with each laser were overlaid to identify colocalization between the blue CGRP fibers and the red synaptophysin puncta, which appear purple. Brightness and contrast were adjusted in Photoshop 5.5 (Adobe Systems, San Jose, CA) for better clarity of the blue-colored staining.

Statistical analysis. The number of DRG neurons were compared among different groups using one-way ANOVA, followed by Tukey's post hoc test. Two-way ANOVA was used to compare the axon growth through different laminas and between the different groups, as well as the changes in PWL over time after different treatments. All data are pre- sented as the mean \pm SD. $p$ values $<0.05$ were considered as statistically significant.

\section{Results \\ Combination of NGF and Sema3A overexpression in adult spinal cord restored normal projection patterns of CGRP ${ }^{+}$ sensory axons after dorsal root injury}

CGRP-positive neurons in the dorsal root ganglion represent a subset of nociceptive neurons that express TrkA receptor tyrosine kinase and require the neurotrophin NGF for survival during development. They send out thinly myelinated or unmyelinated axons peripherally and centrally, and the central axons enter the spinal cord, arborize, and terminate to form synapses within lamina I and outer region of laminar II (IIo) (Snider and McMahon, 1998). Therefore, the distribution of $\mathrm{CGRP}^{+}$nociceptive axons in normal spinal cord is restricted to superficial dorsal horn (Fig. $1 B-D$, left side). In these experiments, dorsal root lesions completely transected all of the sensory axons in the root, causing degeneration of the axons distal to the crush site. The spinal cord becomes denervated, and there is no spontaneous regeneration back into the cord after injury and injection of control GFP encoding virus (Fig. 1 B) (Romero et al., 2001; Tang et al., 2004a,b). As shown previously (Fig. 1C) (Romero et al., 2001; Tang et al., 2004a,b), NGF acts as a potent growth-promoting and attractive molecule for $\mathrm{CGRP}^{+}$nociceptive axons in vivo. The distribution of the regenerating axon projections, however, is remarkably different from that of their normal pattern. It is concentrated around the injection site and lacks a lamina-specific pattern, occupying all of the laminas in the dorsal horn, even extending into the ventral horn. Lamina specificity of neuronal connections to a large extent determines functional specificity in many parts of the vertebrate CNS (Sanes and Yamagata, 1999). Aberrant growth of these sensory axons into deeper dorsal and ventral cord is correlated with several pathological conditions (Wong et al., 2000; Tang et al., 2004a,b; Cameron et al., 2006). It is important, therefore, to instruct regenerating $\mathrm{CGRP}^{+}$axons to terminate within their normal synaptic locations, that is, the superficial dorsal laminas. To achieve this by NGF alone is difficult because axons would be attracted toward and throughout the expression area, and we have been unable to induce laminar-specific NGF expression.

To limit regeneration, Sema3A, a well characterized repulsive guidance molecule, may serve as a good candidate because (1) expression of Sema3A in ventral spinal cord helps to establish the lamina-specific projection of primary sensory axons during development (Messersmith et al., 1995; Fu et al., 2000), and (2) adult sensory neurons express Sema3A receptor neuropilin-1 and plexin-A1 retaining responsiveness to Sema3A (Tanelian et al., 1997; Gavazzi, 2001; Tang et al., 2004b). From previous studies, we knew that simultaneous dorsal expression of Sema3A and NGF could inhibit the sprouting of nociceptive axons in the presence of NGF in non-injured cords (Tang et al., 2004b) or creates an exclusion zone that disrupts the NGF-mediated growth of these fibers during development (Pasterkamp et al., 2000). In preliminary experiments, we found that ventral expression of semaphorin worked best $3 \mathrm{~d}$ after NGF injections. Initially, several injection parameters were tried in which simultaneous injections of NGF and Sema3A encoding adenovirus either (1) fail to support axon regeneration when the Sema3A concentration was too high or (2) did not restrict regeneration to upper dorsal horn when too low (supplemental Fig. 2, available at www.jneurosci. org as supplemental material). Specific temporal and spatial expression of these two antagonistically acting molecules seems im- 

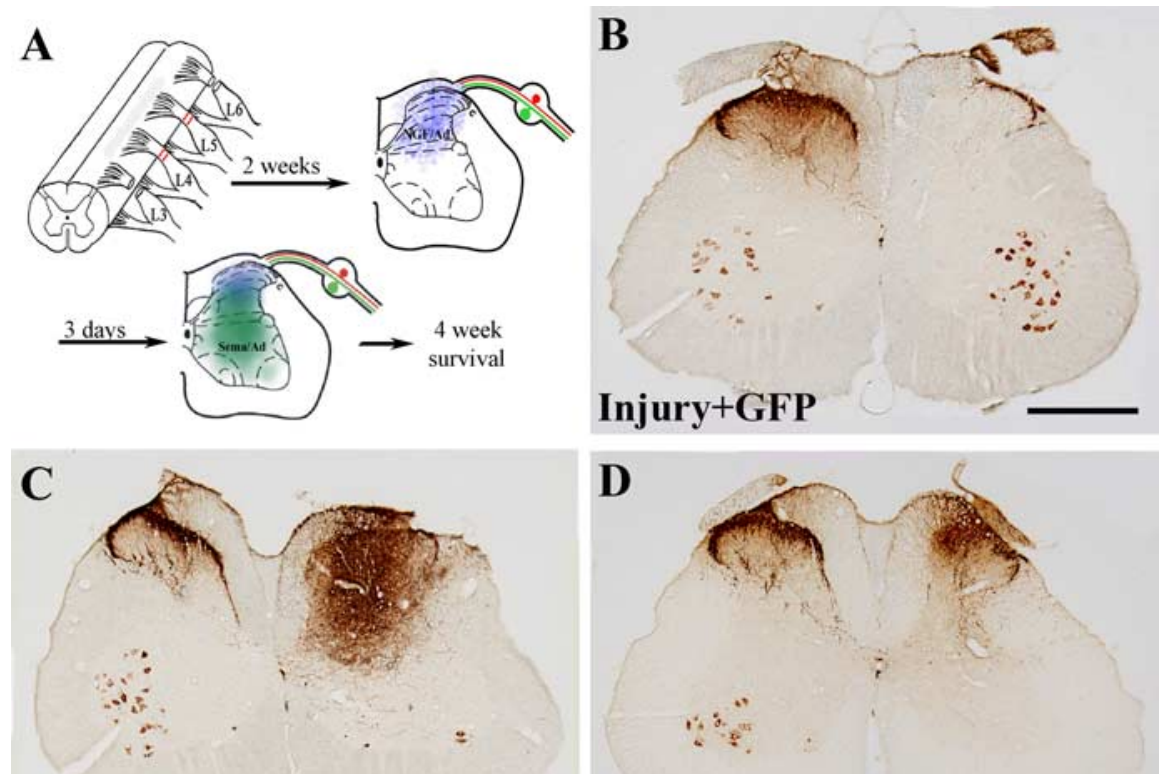

\section{Injury+NGF/GFP}

\section{Injury+NGF/Sema3A}

Figure 1. After dorsal root injury, combined NGF and Sema3A treatment induces and targets CGRP ${ }^{+}$sensory axon regeneration to the superficial dorsal horn. Rat underwent a double-crush injury on right $L 4, L 5$ dorsal roots, and the adjacent $L 3, L 6$ dorsal roots were crushed and tied to prevent collateral sprouting from these segments $(A)$. Two weeks after the injury, individual or combined injections of adenoviruses encoding GFP alone (GFP/Ad, $1.25 \times 10^{6} \mathrm{pfu} / \mu \mathrm{l}$, injection depth of 0.6 and $1.2 \mathrm{~mm}$ ), NGF/GFP (NGF/Ad, $5 \times 10^{4} \mathrm{pfu} / \mu$ l, injection depth of $0.6 \mathrm{~mm}$; GFP/Ad, $1.25 \times 10^{6} \mathrm{pfu} / \mu \mathrm{l}$, injection depth of $1.2 \mathrm{~mm}$ ), or $\mathrm{NGF} / \mathrm{Sema} 3 \mathrm{~A}$ (NGF/Ad, $5 \times 10^{4} \mathrm{pfu} / \mu \mathrm{l}$, injection depth of $0.6 \mathrm{~mm}$; Sema3A/Ad, $1.25 \times 10^{6} \mathrm{pfu} / \mu \mathrm{l}$, injection depth of $1.2 \mathrm{~mm}$ ) were made dorsally into the right $\mathrm{L} 4$, $L 5$ spinal cord. In animals that received NGF plus GFP or Sema3A/Ad injections, the second virus (GFP or Sema3A/Ad) was given $3 \mathrm{~d}$ after NGF/Ad injection. Four weeks after virus injection, rats were killed, and the distribution of CGRP-containing sensory axons were examined within the spinal cord by immunohistochemistry ( $\boldsymbol{B}-\boldsymbol{D}$; the left side shows sham control, whereas the right is the experimental side). After dorsal root injury, $\mathrm{CGRP}^{+}$axons are absent from this region of the spinal cord, except for a small number of collateral fiber in Lissauer's tract, as seen in the GFP/Ad injection group $(\boldsymbol{B})$. No spontaneous regeneration into the spinal cord occurred for up to 6 weeks after the injury. NGF overexpression in dorsal cordinduced extensive regeneration of $\mathrm{CGRP}^{+}$axons into the injection area $(\boldsymbol{C})$, which occupied all dorsal laminas and extended into ventral spinal cord. NGF and Sema3A/Ad were used together to introduce attractive ( $A$, blue color) and repulsive ( $\boldsymbol{A}$, green color) gradients into different regions of the spinal cord. They work coordinately to induce and target CGRP ${ }^{+}$axon regeneration into the superficial dorsal horn (D), which shows a similar distribution to that of the normal spinal cord (left side). Scale bar, $0.5 \mathrm{~mm}$ ance studies indicate that the growth cone response to guidance cues depends on the nature, dosage, presentation of the cue, and the internal state of the neuron. Our in vivo findings are consistent with those studies and demonstrate that regenerating axons require similar precision in the expression of guidance cues for proper targeting of regenerating axons within the adult spinal cord.

To further study the lamina-specific regeneration induced by $\mathrm{NGF} / \mathrm{Sema} 3 \mathrm{~A}$ treatment, $\mathrm{CGRP}^{+}$axon growth in each of the relative spinal cord laminas (I-VI) was quantified (Fig. 2A). The distribution pattern was analyzed in normal spinal cord and spinal cords after injury receiving different treatments (Fig. 2B). A two-way ANOVA with repeated measures showed a significant main effect for lamina-specific innervation among treatment groups $\left(F_{(3,96)}=36.27 ; p<0.01\right)$. In normal spinal cord, the majority of $\mathrm{CGRP}^{+}$axons are located in laminas I and II (lamina I, 19\%; II, 52\%; III, 18\%; IV, 10\%; V, 1\%; $n=6)$. Dorsal root lesions and injection of GFP/Ad into superficial and deep spinal cord regions resulted in no quantifiable axonal regeneration into the spinal cord. Superficial NGF and deep GFP (NGF/ GFP) treatment induced copious amount of regeneration into all six dorsal laminas (lamina I, 5\%; II, 17\%; III, 25\%; IV, 24\%; V, 20\%; VI, 9\%; $n=6$ ). This distribution was significantly different from normal $\left(F_{(1,10)}=72.6 ; p<0.01\right)$. In contrast, $\mathrm{NGF} / \mathrm{Sema3A}$-induced regeneration was more confined to laminas I and II (lamina I, $12 \%$; II, 36\%; III, 27\%; IV, 11\%; V, 9\%; VI, $5 \% ; n=5)$. This effect was signifiportant in shaping the distribution of $\mathrm{CGRP}^{+}$fiber regeneration (Fig. 1A).

For the remaining experiments 2 weeks after dorsal root injury, NGF-expressing virus $\left(5 \times 10^{4} \mathrm{pfu} / \mu \mathrm{l}\right)$ was injected $0.6 \mathrm{~mm}$ deep (superficial) into the spinal cord. This 2 week waiting period allows for injured axons to regenerate up to the surface of the cord and examination of preregenerative nociceptive latencies. Three days after NGF injections, Sema3A-expressing virus $\left(1.25 \times 10^{6} \mathrm{pfu} / \mu \mathrm{l}\right)$ was injected into the same area, only $0.5 \mathrm{~mm}$ deeper (deep) than the NGF injection site. Axonal regeneration into the spinal cord was examined 4 weeks after Sema3A/Ad injections. Regenerating CGRP ${ }^{+}$axons terminated within the superficial dorsal horn, resembling the distribution of projections of CGRP-positive axons within the normal spinal cord (Fig. 1D). Only with a temporal delay in semaphorin expression within the ventral horn at the high dose were regenerating fibers restricted to the upper dorsal horn. The delay in Sema3A expression could activate NGF-mediated responses to elicit regeneration before the establishment of the inhibitory gradient, and, as these axons enter the more ventrally organized semaphorin gradient, their growth is restricted. Thus, the growth pattern was not only affected by the dosage and spatial organization but also the temporal expression of the two opposing gradients. Current axon guidcantly different from the NGF/GFP treatment group $\left(F_{(1,9)}=\right.$ $63.4 ; p<0.01)$ but not from normal spinal cord $\left(F_{(1,9)}=0.1 ; p>\right.$ $0.1)$. These data show that Sema3A expression reduced NGFinduced axon growth into deeper laminas, and the combination of NGF/Sema3A treatment restored a normal-like laminaspecific distribution of $\mathrm{CGRP}^{+}$axons in spinal cord.

\section{Sema3A overexpression within the spinal cord delineates an exclusion zone for regenerating CGRP ${ }^{+}$axons}

To directly identify the relationship between Sema3A overexpression and the establishment of lamina-specific CGRP ${ }^{+}$axonal regeneration, a myc antibody was used to visualize virusmediated Sema3A expression. Spinal cord sections from NGF/ Sema3A-treated rats were double stained by myc and CGRP immunohistochemistry (Fig. $3 A, B$ ). Sema3A overexpression was primarily concentrated to the ventral and intermediate part of the spinal cord but extended into the dorsal cord (Fig. 3B). Overlaid images in Figure 3, $C$ and $D$, show $\mathrm{CGRP}^{+}$axons terminating at the dorsal extent of the Sema3A expression zone. The Sema3A appeared to form an "inhibitory boundary" for adult regenerating $\mathrm{CGRP}^{+}$axons, reminiscent of that observed by Fu et al. (2000). Therefore, virus-induced Sema3A expression within the deeper dorsal laminas restricts NGF-induced regeneration to su- 
perficial laminas and, thus, more accurately directs reconstruction of a normallike termination pattern for these regenerating axons.

\section{NGF and Sema3A treatment regulates regeneration of substance- $\mathrm{P}^{+}$ nociceptive axons in spinal cord}

In adult dorsal root ganglion, at least two classes of nociceptive neurons exist (Snider and McMahon, 1998). One expresses neuropeptide CGRP and/or SP, NGF, and receptor tyrosine kinase TrkA and projects to laminas I and IIo of spinal cord (accounting for $\sim 40-45 \%$ of DRG neurons); another expresses enzymes FRAP and TMP, glial cell line-derived neurotrophic factor (GDNF) receptor c-Ret, binds lectin IB4, and projects to lamina IIi (accounting for $~ 30-35 \%$ of DRG neurons) (Molliver et al., 1997). We showed previously that intact $\mathrm{SP}^{+}$nociceptive axons are sensitive to NGF and Sema3A treatment (Tang et al., 2004b). To examine whether injured axons from different subpopulations of nociceptive neurons react to NGF and Sema3A treatment, we stained the spinal cord for SPcontaining and IB4-binding nociceptive axons after different treatments (Fig. 4). We found that injured $\mathrm{SP}^{+}$fibers respond similarly to NGF and Sema3A overexpression as $\mathrm{CGRP}^{+}$fibers (Fig. 4G). From previous studies, we know that NGF induces extensive regeneration of $\mathrm{SP}^{+}$fibers into the NGF/Ad injection area, and here we show that the combination of $\mathrm{NGF} /$ Sema3A also restricted these axons to the superficial dorsal horn. However, injured IB4-binding nociceptive axons were unaffected by NGF or Sema3A treatment and remained absent from the spinal cord after treatment (Fig. $4 F, H$ ).

\section{NGF/GFP and NGF/Sema3A treatment induced sensory axon regeneration into the spinal cord, as well as axon sprouting from high lumbar regions}

Previous studies suggested that NGFinduced regrowth of nociceptive axons in the spinal cord could be from two sources: regeneration of injured axons or sprouting of intact axons from upper or lower spinal segments and possibly the pia (Romero et al., 2001; Tang et al., 2004a). In this study, we used two retrograde tracers to confirm sensory axon regeneration after NGF and NGF/Sema3A treatment. First, immediately after L4, L5 dorsal root injury, FG was injected into the lesion site to label all of the injured sensory neurons in L4 and L5 DRGs. Two weeks later, the animals then received GFP/Ad, NGF+GFP/Ad, or NGF+Sema3A/Ad injections. Three weeks after virus injection (and 1 week before the animals were killed), a small amount of a second tracer, dextran-TR, was injected into the L4 and L5 region of the spinal cord. This should label axons that have either regenerated into the spinal cord from the lesioned dorsal root or
B

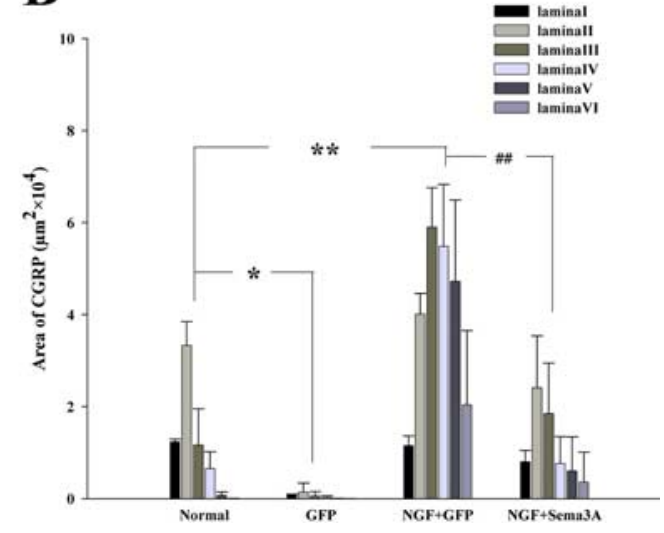

Figure 2. NGF/Sema3A treatment restored lamina-specific projections of CGRP ${ }^{+}$axons after dorsal root injury. To quantify the laminar distribution of regenerated axons, a mask of six consecutive boxes were drawn on the representative image of normal spinal cords, outlining spinal cord laminas $I-\mathrm{VI}(\boldsymbol{A})$. This was used as a template and applied to the appropriate position of the in superficial laminas I and II. Dorsal root injury almost completely abolished CGRP fibers in all laminas. NGF treatment induced robust regeneration of axons in all laminas, which is significantly different from the normal distribution. In contrast, NGF/Sema3AScale bar, $0.5 \mathrm{~mm}$. Values represent mean \pm SD; $n=3-6 .{ }^{*} p<0.05,{ }^{* *} p<0.01$ compared with normal spinal cord; ${ }^{\# \#} p<0.01$
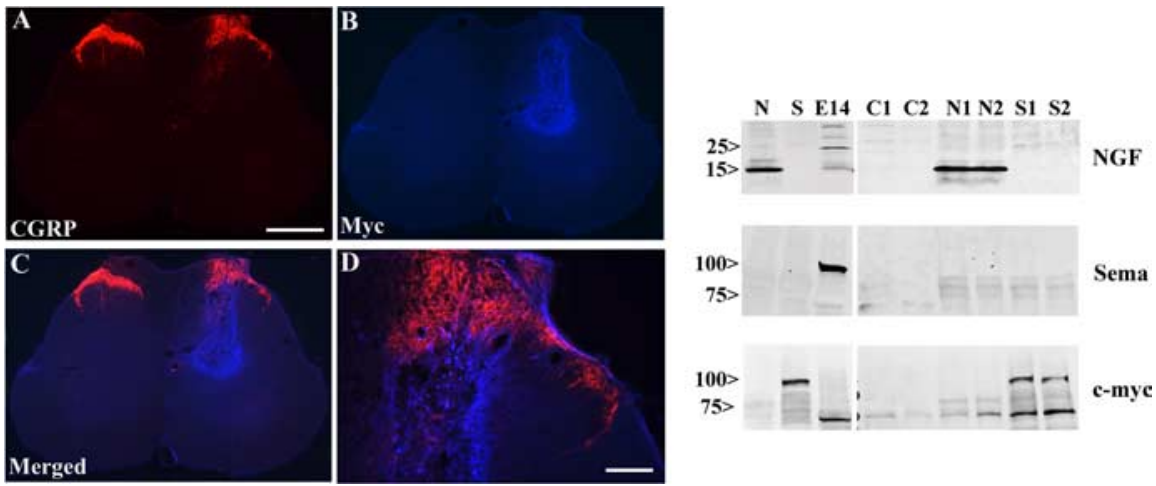

Expression of endogenous and induced expression of NGF and semaphorin $3 A$ within the spinal cord. In NGF/Sema3Aside). Virus-derived Sema3A expression was visualized by anti-myc antibody ( $\boldsymbol{B}$, blue) and extended throughout laminas III-VI.

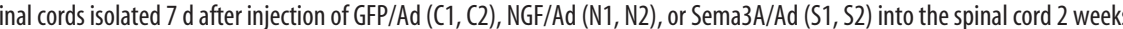
semaphorin $3 \mathrm{~A}$ is identified within any treatment groups using a rat-specific semaphorin $3 \mathrm{~A}$ antibody (Sema) but is clearly expressed in rats treated with Sema3A/Ad and stained with antibodies that recognize the c-myc epitope $\operatorname{tag}(\mathrm{c}-\mathrm{myc})$. Blots on left show staining in positive controls, purified NGF (N), or semaphorin 3A (S) and embryonic day 14 spinal cord (E14).

sprouted from non-injured axons from the dorsolateral tract of Lissauer or from the pia. The pia is highly innervated with peripheral nociceptive axons that might sprout into the spinal cord in response to NGF. The needle was also inserted at the midline at an angle to minimize tracer leakage past the DREZ and into the dorsal root. In the first experiment to assess the extent of sprouting, dorsal roots L3-L6 were cut and tied to prevent regeneration into these nerves, whereas L2 was left intact (Table 1). After the animals were killed, L2, L3, L4, and L5 DRGs were extracted and sectioned, and the number of labeled neurons were counted in each DRG. The logic of this scheme was to assess the relative contribution of nociceptive axons sprouting from the L2 spinal cord region or peripheral pial axons sprouting from L4 and L5 DRG neurons versus regenerating axons. Counting Texas Red- 
SP
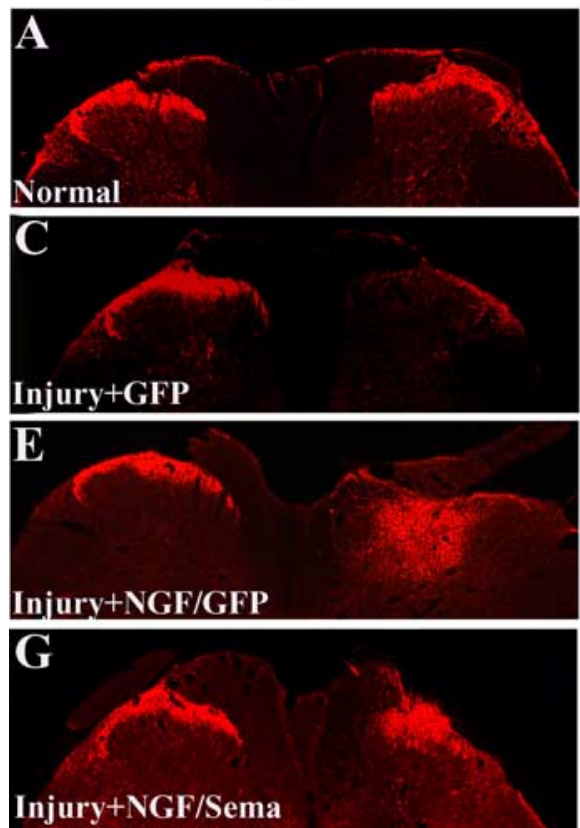

IB4
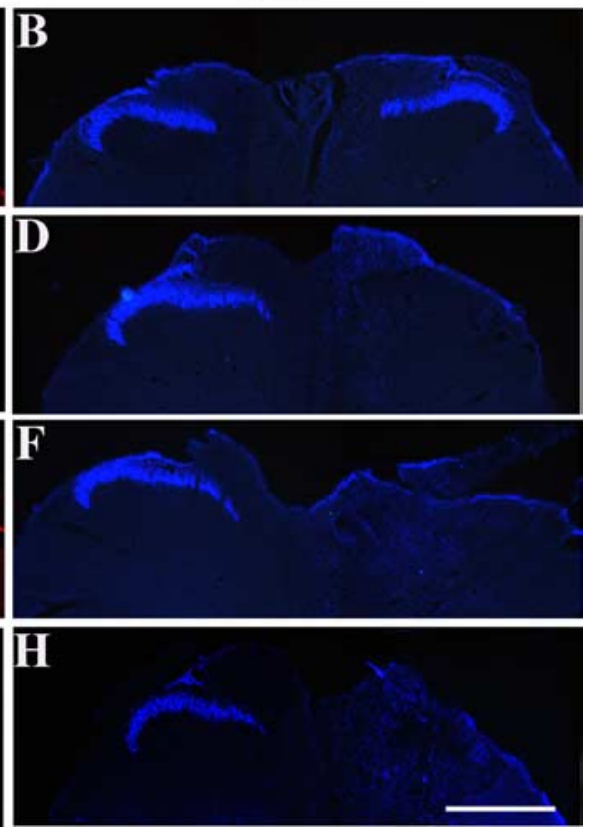

Figure 4. NGF/Sema3A overexpression targeted regeneration of injured $\mathrm{SP}^{+}$nociceptive axons to superficial dorsal horn. Sections were colabeled using SP and IB4 immunohistochemistry to identify two classes of nociceptive axons. SP-containing axons normally terminate at laminas I and II (left side in $\boldsymbol{A}, \boldsymbol{C}, \boldsymbol{E}, \boldsymbol{G}$ ) and disappeared after dorsal root injury (C). NGF/GFP overexpression induced extensive regeneration of SP axons into the dorsal horn $(\boldsymbol{E})$, and NGF/Sema3A overexpression reduced axon growth into deeper laminas, shaping regenerating axons toward a normal distribution $(\boldsymbol{G})$. IB4-binding nociceptive axons normally terminate at inner aspect of lamina II (left side in $\boldsymbol{B}, \boldsymbol{D}, \boldsymbol{F}, \boldsymbol{H}$ ), and NGF/GFP $(\boldsymbol{F})$ or NGF/Sema3A $(\boldsymbol{H})$ treatment has no effect on this class of axons after injury. Scale bar, $0.5 \mathrm{~mm}$.

Table 1. Number of Texas Red-labeled DRG neurons from axons that have sprouted into the L4/L5 region of the spinal cord from L2 or meninges 4 weeks after treatment

\begin{tabular}{llrl}
\hline \multirow{2}{*}{ Group } & \multicolumn{4}{l}{ Number of TR-labeled cell in DRG } \\
\cline { 2 - 4 } & $\mathrm{L} 2$ & \multicolumn{1}{l}{$\mathrm{L} 3$} & $\mathrm{~L} 4, \mathrm{~L}^{a}$ \\
\hline NGF + GFP & $218 \pm 132$ & $21 \pm 8$ & $44 \pm 39$ \\
NGF + Sema & ND & $9 \pm 9$ & $\mathrm{ND}$ \\
\hline
\end{tabular}

Values represent mean \pm SD, $n=3$.

${ }^{a}$ Values indicate peripheral axon regeneration after cutting and tying dorsal roots $\mathrm{L} 3-\mathrm{L} 6$ to prevent regeneration.

Table 2. Number and percentage of FG/Texas red-colabeled neurons in L4, L5 DRGs

\begin{tabular}{llccc}
\hline \multirow{4}{*}{ Group } & \multicolumn{4}{l}{ Cell number in L4, L5 DRG } \\
\cline { 2 - 5 } & FG & TR & Colabeled & (Colabeled:FG)\% \\
\hline GFP & $2150 \pm 666$ & $5 \pm 2$ & $5 \pm 2$ & $0.2 \pm 0.1$ \\
NGF + GFP & $2574 \pm 1242$ & $448 \pm 228$ & $407 \pm 218$ & $15.3 \pm 2.8^{*}$ \\
NGF + Sema & $2673 \pm 717$ & $240 \pm 80$ & $236 \pm 77$ & $8.9 \pm 1.4^{*, * *}$ \\
\hline
\end{tabular}

Values represent mean $\pm S D, n=3 .{ }^{*} p<0.01$ compared with GFP group; ${ }^{* *} p<0.05$ compared with NGF + GFP group, analyzed by one-way ANOVA.

labeled neurons within the L2-L5 DRGs correspond to axon sprouting from non-injured axons within Lissauer's tract and pial sprouting from peripheral nerves, respectively (Table 1). As previously hypothesized, the vast majority of sprouting axons within treated spinal cords arose from non-injured axons in Lissauer's tract, and very few were derived from the pia at all levels (Table 1).

To examine regenerating axons from L4 and L5 DRGs, a second series of experiments were conducted. For these experiments, the percentage of neurons with regenerating axons was calculated by dividing the number FG/TR-colabeled neurons by the number of FG-labeled neurons (Table 2). Because regenerat- ing axons stop at the DREZ and no axons regenerate into the spinal cord after GFP/Ad treatment, the colabeled DRG neurons in this group should represent the nonregenerated neurons taking up tracer leaking past the DREZ. This turned out to be very few neurons (Table 2, Fig. $5 A-C$ ). There were many more colabeled neurons in both NGF/GFP $(448 \pm 218)$ and NGF/ Sema3A $(240 \pm 80)$ groups (Table 2, Fig. $5 D-I)$. This suggested that NGF or NGF/ Sema3A treatments induced a considerable proportion of DRG neurons to regenerate into the spinal cord. Thus, CGRP ${ }^{+}$ or $\mathrm{SP}^{+}$axons observed within the spinal cord for these treatment groups can mostly be attributed to regenerated fibers. Furthermore, costaining these DRG sections using CGRP antibodies confirmed the vast majority $(>90)$ of regenerating axons to be from CGRP-positive neurons (Fig. 5J,K)

\section{Targeted regeneration of nociceptive axons induced by NGF/Sema3A overexpression led to recovery of nociceptive function}

The majority of sensory information from the rat hindlimb is transferred to the spinal cord by the ipsilateral dorsal roots L2L6, in which CGRP ${ }^{+}$and $\mathrm{SP}^{+}$axons mediate cutaneous nociceptive sensation. Nociception of the hindlimb can be tested by measuring PWL in response to radiant heat applied to the plantar surface of the rat hindlimb. Previously, we demonstrated that lesioning of these dorsal roots caused a complete loss of paw withdrawal response on the ipsilateral side, and NGF-induced regeneration of nociceptive axons into the spinal cord resulted in recovery of nociceptive function and a reduction in PWL (Romero et al., 2001). However, the extent of recovery was dependent of the number of regenerating axons (Tang et al., 2004a). In this study, we examined whether NGF/Sema3A-induced and targeted axonal regeneration caused nociceptive functional recovery, and whether differences in the distribution of nociceptive axons resulted in different nociceptive responses. PWL was measured before and once a week after injury and treatment (Fig. 6A). Analysis using two-way ANOVA with repeated measures showed a significant main effect in latencies between treatment groups $\left(F_{(2,91)}=\right.$ $21.74 ; p<0.01)$. In all groups, ipsilateral PWL rose to the cutoff value after injury because of the absence of a withdrawal response. No recovery of PWL was observed in the GFP/Ad group throughout the experimental period. When compared with controls, both NGF+GFP/Ad $\left(F_{(1,9)}=40.4 ; p<0.001\right)$ and $\mathrm{NGF}+$ Sema3A/Ad $\left(F_{(1,8)}=28.0 ; p<0.01\right)$ injected animals showed a decrease in PWL starting 1 week after injection and recovered the PWL to near-normal level 3-4 weeks after injections $(n=5)$, indicating an almost complete functional recovery. There was no statistical difference in PWL response times between NGF/GFP and NGF/Sema3A groups $\left(F_{(1,9)}=1.5 ; p>\right.$ $0.05)$. No significant thermal hyperalgesia or mechanical allodynia developed in the NGF/GFP group (data not shown) within the observation period of this experiment. In addition, PWL returned to the pretreatment levels after relesioning of only L4 and 
L5 dorsal roots in both NGF/GFP and NGF/Sema3A groups (Fig. 6B), further validating that functional recovery was mediated solely by regeneration of nociceptive axons.

\section{Regenerated nociceptive axons form} synaptic connections in spinal cord The recovery of nociceptive function induced by NGF/GFP and NGF/Sema3A treatment indicated that regenerated nociceptive axons form synapses with secondary neurons in the spinal cord. To confirm synaptic formation and distribution, we double stained the spinal cords for CGRP and a presynaptic terminal marker, synaptophysin. Confocal microscopy showed colocalization of CGRP- and synaptophysin-containing puncta in spinal cords (Fig. 7). In non-injured spinal cords, the majority of these synapses ( $91 \pm$ $3.4 \%$ ) were localized to laminas I and II, representing the normal innervation area of $\mathrm{CGRP}^{+}$primary nociceptive fibers. In the NGF/GFP treatment group, CGRPpositive axons displayed a network of synapses that extended throughout the dorsal horn, with the highest densities ( $51 \pm 5 \%$ ) being localized to ectopic regions (Fig. 7C). Coinjection of Sema3A after NGF treatment showed a synaptic distribution that was similar to normal spinal cord, with the highest density of synapses (95 \pm $3.3 \%$ ) being localized to laminas I and II and very few identifiable synapses within the deeper laminas. The distribution of synapses localized to laminas I and II for both control and NGF/Sema3A were statistically higher $(p<0.01)$ than those in laminas I and II for NGF/GFP. These data indicate that the use of developmental guidance factors can improve the specificity of axon regeneration, increasing appropriate targeting and formation of synaptic terminals, and thus, enhance the probability to form appropriate functional connections.

\section{Discussion}

During development, axonal pathfinding and targeting are highly dependent on a multitude of guidance molecules genetically regulated to produce precise temporal and spatial expression patterns (Dickson, 2002; Osterfield et al., 2003). Migrating growth cone sample and integrating these guidance signals to generate final pathway decisions ultimately directing them to their synaptic targets for proper function (Dickson, 2002; Osterfield et al., 2003). Disruption in pathway guidance can lead to a spectrum of morphological and behavioral abnormalities (Osterfield et al., 2003). In the adult, particularly after injury, these signals are either not present or disrupted by the overt inhibitory nature of the CNS (Doucet and Petit, 2002; de Wit and Verhaagen, 2003; Silver and Miller, 2004). To overcome this inhibitory environment, numerous growth-promoting strategies have been examined in multiple regenerative models. Histological examination consistently shows regenerating spinal cord axons not following their developmental pathways and often growing in diffuse and tortuous patterns, which aids their identification (Steward et al., 2003). The targeting parameters of such regenerating axons are rarely examined, and behavioral outcome measures are usually the standard in determining functional restoration of the damaged circuit. To obtain the highest functional return from the few axons that regenerate, strategies need to be developed not only to overcome the inhibitory environment but also to guide and target regenerating axons. This has become evident with recent studies showing that either stem cell or olfactory ensheathing cell transplants influence the growth of multiple pathways, not only increasing the prospects of functional regeneration of motor systems but concomitantly induce sprouting of CGRP ${ }^{+}$axons into deeper dorsal laminas, resulting in allodynia (Hofstetter et al., 2005; Richter et al., 2005).

The administration of neurotrophin alone or in combination with other proregenerative compounds has been shown to dramatically improve regeneration after spinal cord injury (Coumans et al., 2001; Romero et al., 2001; Ruitenberg et al., 2003; Lu et al., 2004); however, these molecules are not effective at targeting axon. Any strategy to promote regeneration at best only supports the regeneration of a small percentage of lesioned axons and show little functional recovery. In response to the low numbers of regenerating axons observed in all models, the importance of directing the growth of those axons to their target locations be- 

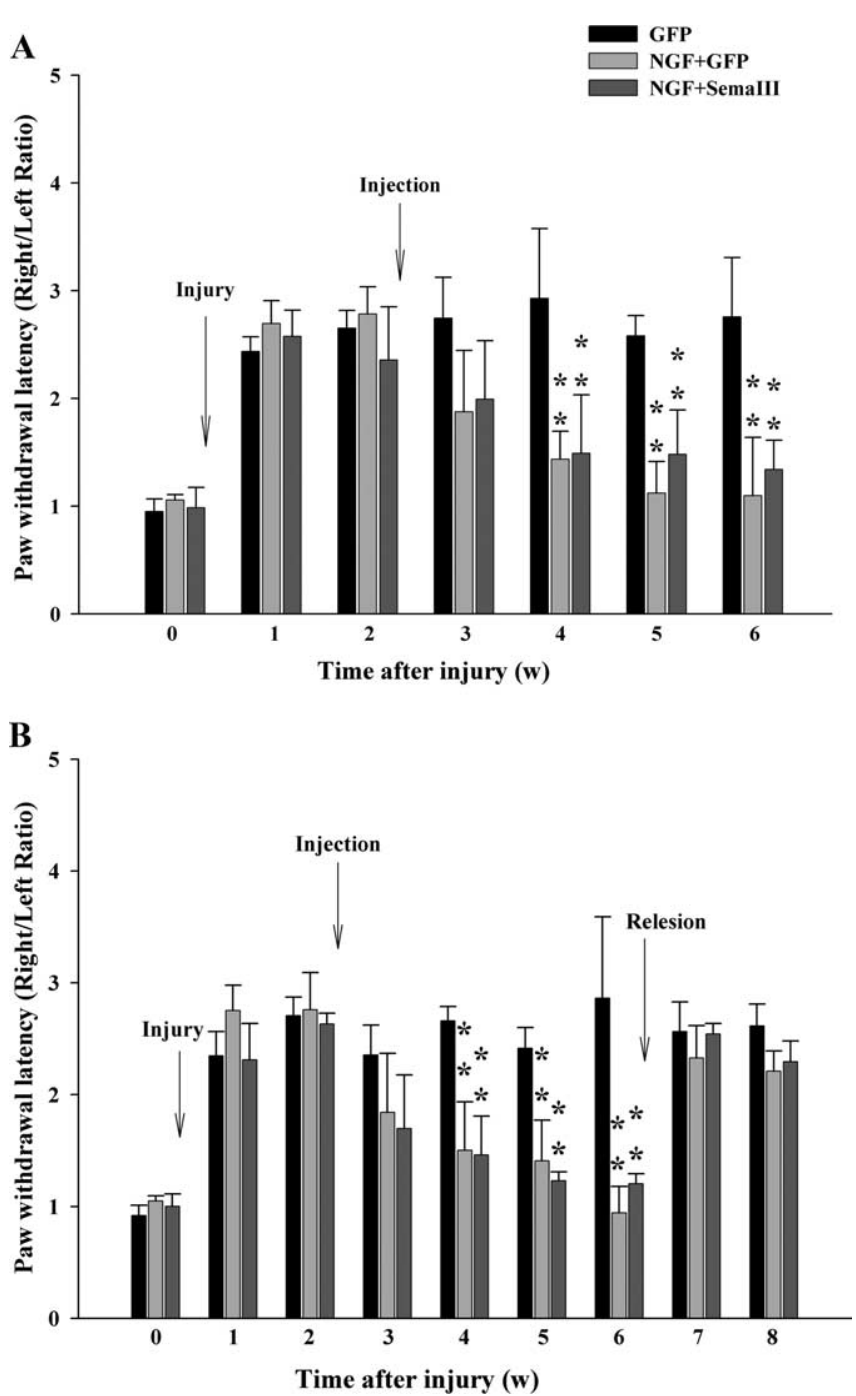

Figure 6. Both NGF/GFP- and NGF/Sema3A-induced axon regeneration leads to near complete functional recovery of thermal nociception. PWL was measured on both right and left hindlimbs before and once a week after injury and treatment. The ratios of right (experimental) and left (control) hindpaw latencies were compared to examine the influence of different treatments on nociceptive functions. $A, L 4, L 5$ dorsal root injury caused an immediate loss of paw withdrawal response, raising the ipsilateral PWL to the cutoff value. No spontaneous recovery of PWL was found in GFP/Ad-treated rats. NGF/GFP and NGF/Sema3A treatments induced recovery of nociceptive function and decreased PWL to near-normal levels by the end of the study. There is no significant difference in PWL between these two groups throughout the observation time. PWL recovery disappeared after relesioning the $L 4$ and $L 5$ dorsal roots in either $\mathrm{NGF}+\mathrm{GFP} / \mathrm{Ad}$ - or NGF + Sema3A/Ad-treated rats $(\boldsymbol{B})$, indicating that the recovery was attributed to regenerating sensory axons and not axon sprouting. Values represent mean $\pm S D ; n=$ $5-6 .{ }^{*} p<0.05,{ }^{* *} p<0.01$, analyzed by two-way ANOVA.

comes paramount. In addition, the use of growth-promoting agents such as neurotrophins increase the prospect of axons regenerating into generalized regions with less targeting capability, because regeneration is dependent on regions in which the growth factor is present (Blesch et al., 2002). Very few studies have examined synaptic connections let alone the specificity of the targets after axonal regeneration, and much of the recovery associated with regenerating axons may be attributable to supraspinal reorganization of circuits or contralateral sprouting to establish novel functional circuits (Fouad et al., 2001; Kim et al., 2006). Equally as important to targeting and enhancing the efficiency of regenerating circuits is the elimination of aberrant connections, which could either cause detrimental function (e.g., pain and autonomic dysreflexia) (Romero et al., 2000; Cameron et al., 2006) or diverge to coactivate both motor inhibitory and excitatory circuits to reduce overall functional recovery.

During spinal cord development, sensory axons bypass inappropriate lamina and project directly to their target lamina (Ozaki and Snider, 1997; Sharma and Frank, 1998) in which they establish lamina-restricted synaptic terminals (Sanes and Yamagata, 1999). For TrkA-positive (peptidergic nociceptive) axons, entry into the spinal cord and projection into laminas I and II correlate with the ventral migration of a chemorepulsive gradient established by semaphorin 3A expression (Fitzgerald et al., 1993; Messersmith et al., 1995; Wright and Snider, 1995; Puschel et al., 1996; Fu et al., 2000). In the embryo, as fibers enter and begin to form arbors, semaphorin $3 \mathrm{~A}$ expression extends high into the dorsal horn. During this period, the addition of exogenous NGF has little effect on their ventral-mediated growth. As sensory axon growth continues, the semaphorin $3 \mathrm{~A}$ gradient migrates ventrally, and, at these early postnatal time points, exogenous NGF increases growth over dorsal as well as ventral regions (Redmond et al., 1997). This alteration in NGF sensitivity to elicit axon growth throughout the dorsal and ventral horns correlates with the dorsal reduction in semaphorin $3 \mathrm{~A}$ expression, which in the adult persists only in motor neurons (Puschel et al., 1996; Pasterkamp et al., 2000). Thus, semaphorin $3 \mathrm{~A}$ has the ability to modulate NGF-induced axon growth even during development.

In the present study, the production of opposing guidance cue gradients were used to target the regeneration of primary peptidergic nociceptive axons to their dorsal lamina. Dorsal expression of NGF was used to induce regeneration of nociceptive axons into the spinal cord; however, as demonstrated in previous studies, these axons fail to terminate in their normal targets and continue to extend throughout the entire dorsal horn and, in some cases, extend into the ventral horn as well (Romero et al., 2001). To restrict these axons from regenerating into the deeper dorsal or ventral horns, semaphorin $3 \mathrm{~A}$ was expressed within the ventral horn. It is proposed that this molecule produces a gradient for repulsion to commence (Kolodkin 1996; Nakamura et al., 2000). Although the extent of the gradient was difficult to quantify by immunofluorescence, the genetic method for cellular expression of these factors would provide a localized production source, and the secretion of either NGF or Sema3A would necessitate the production of a gradient extending outward from the local source of production (Cao and Shoichet, 2003; Heron et al., 2006; Taylor et al., 2006). Our results with NGF/ Sema3A-treated rats suggest that regenerating axons encountered a permissive environment (provided by NGF) within the superficial layers of the dorsal horn and then stop in contact with Sema3A, in which the overall signal becomes inhibitory. The pattern of adult CGRP-positive axons terminating growth at the dorsal aspect of the Sema3A gradient appear almost identical to the developmental patterning of TrkA-positive axons encountering Sema3A in the chick embryo (Shepherd et al., 1997; Fu et al., 2000). Likewise, this patterning led to a regional distribution of synapses for regenerating nociceptive axons that were primarily confined to laminas I and II. This matched the synaptic distribution of these axons in the normal cord, although at a significantly lower density. Expression of NGF alone led to a dramatically different synaptic patterning that was more evenly distributed throughout all laminas within the dorsal horn. Retrograde track tracing experiments also demonstrated that coexpression of semaphorin resulted in a $>40 \%$ reduction in the total number of regenerating nociceptive axons when compared with NGF but no reduction in functional recovery. This is in contrast to our previous studies that show that similar reductions in nontargeted regenerating nociceptive axons result in a sub- 
stantial reduction in functional recovery (Tang et al., 2004a), indicating that, although coexpression of sema3 A resulted in fewer regenerating axons, more precise laminar targeting of synaptic connection increased the overall efficacy of the reconstructed circuits to enhance functional return.

Our previous studies indicate that NGF-mediated ectopic sprouting of noninjured CGRP-positive sensory axons into deeper spinal cord laminas are involved in the onset of chronic pain and autonomic dysreflexia (Romero et al., 2000; Cameron et al., 2006). In the present study, indicators of chronic pain behavior such as thermal hyperalgesia and mechanical allodynia were not manifested in animals treated with either NGF/GFP or NGF/ Sema3A, and the incidences of autonomy diminished in both groups. The failure of regenerating axons to form functional synapses is an unlikely reason for this unusual behavior for two reasons. First, reestablishment of normal protective pain, indicative of paw withdrawal to heat, strongly suggests that regenerating axons make functional synapses onto neurons that form this synaptic reflex. Second, analysis of synapse formation by double labeling CGRPpositive axons for synaptophysin demonstrated extensive ectopic synapses in the deeper dorsal laminas after treatment with NGF/GFP but not NGF/Sema3A. So why do ectopic synapses from regenerating axons fail to elicit chronic pain? One possibility is that other sensory pathways contribute to the progression of chronic pain, and the regeneration of a single pathway or axon population is insufficient (Neumann et al., 1996; Vulchanova et al., 2001; Braz et al., 2005). In the present study, regeneration of the IB4positive $\mathrm{C}$-fiber and A- $\beta$ myelinated axons were not observed. These axons are thought to regulate pain response, and their absence may prevent convergent signals that induce neuropathic pain. Another possibility is the number of regenerating axons provided an insufficient driving force to elicit chronic pain. In both NGF treatment groups, only a fraction $(\sim 25-50 \%)$ of the total number of C-fibers regenerated, and receptor field signaling to neurokinin-1 neurons might not be sufficient to trigger chronic pain responses. A final possibility is that the 4 week time window for posttreatment behavioral analysis was too short to support sufficient maturation of normal or ectopic synapses to display pathological symptoms and that these behavioral outcomes will increase over time. These possibilities and several others are presently being addressed.
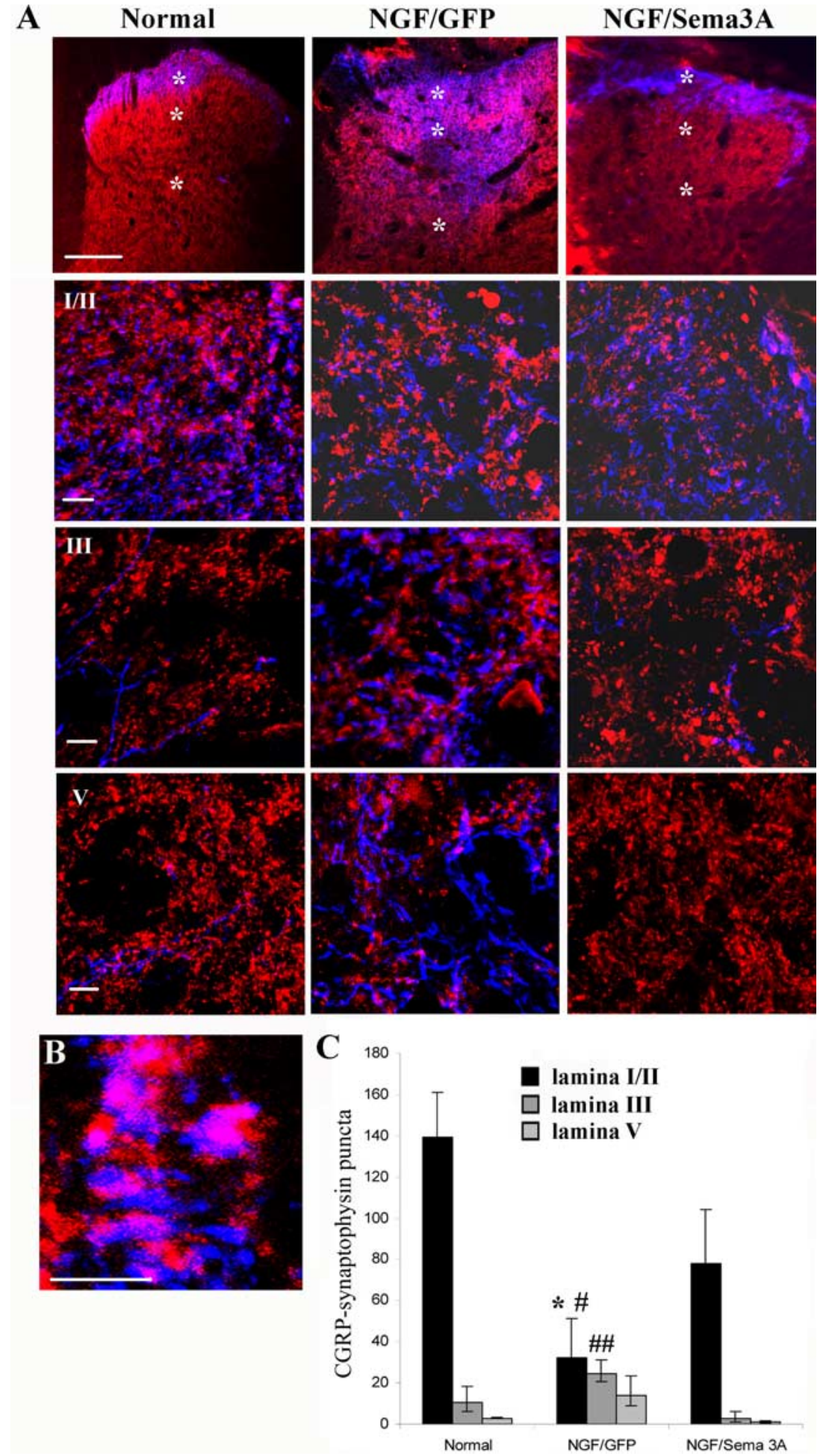

Figure 7. Confocal microscopy images of synaptic-like structures associated with regeneration of $\mathrm{CGRP}^{+}$nociceptive axons in the spinal cord. The spinal cord was double stained for (GRP (blue) and presynaptic protein synaptophysin (red). Colabeling for CGRP and synaptophysin (violet) showed the presence of synaptic clusters associated with regenerated $\mathrm{GRP}^{+}{ }^{+}$nociceptive axons within the dorsal horn. $A$, Colocalization of CGRP and synaptophysin staining in normal (control) dorsal horn or after treatment with either NGF/GFP or NGF/Sema3A. Synaptic profiles from different laminas are restricted to the superficial dorsal laminas after NGF/Sema3A treatment similar to that of the control. Scale bar, $100 \mu \mathrm{m}$. Higher magnification within laminas I, III, and V confirm lower density of synaptic profiles in laminas III and V after NGF/Sema3A treatment but not NGF/GFP treatment. Scale bar, $10 \mu \mathrm{m} . \boldsymbol{B}$, High-resolution confocal microscopy was used to visualize individual CGRP-synaptophysin vesicle clusters (purple). Scale bar, $5 \mu \mathrm{m}$. C, Graph showing the distribution of synaptic profiles within laminas $\mathrm{I} / \mathrm{II}, \mathrm{III}$, and V. Counts represent colabeled synaptic puncta $\geq 1 \mu \mathrm{m}^{2}$ from regions $100 \times 100 \mu \mathrm{m}$ within lamina represented in photographs in $\boldsymbol{A}$. The vast majority of synaptic profiles were localized to laminas $\mathrm{I} / \mathrm{l}$ for both normal and NGF/Sema3Atreated cord, whereas synapses were more evenly distributed throughout all laminas with NGF/GFP treatment. Values represent mean \pm $\mathrm{SD} ; n=3 .{ }^{*} p<0.001$ compared with lamina I/II of normal spinal cord; ${ }^{\#} p<0.01$ compared with laminas I/II of NGF/Sema3A-treated cords; $\#$ $p<0.01$ compared with lamina III of NGF/Sema3A cords, analyzed by two-way ANOVA. 
In summary, the combination of NGF and Sema3A in this study induced targeted axon regeneration and synaptic formation into the denervated spinal cord, which led to successful nociceptive functional recovery. It provides insights of using developmental guidance cues to reestablish specific neuronal connections in adult CNS, which is essential for optimal longterm functional recovery.

\section{References}

Aldskogius H, Kozlova EN (2002) Strategies for repair of the deafferented spinal cord. Brain Res Brain Res Rev 40:301-308.

Blesch A, Lu P, Tuszynski MH (2002) Neurotrophic factors, gene therapy, and neural stem cells for spinal cord repair. Brain Res Bull 57:833-838.

Braz JM, Nassar MA, Wood JN, Basbaum AI (2005) Parallel "pain" pathways arise from subpopulations of primary afferent nociceptor. Neuron 47:787-793.

Cameron AA, Smith GM, Randall DC, Brown DR, Rabchevsky AG (2006) Genetic manipulation of intraspinal plasticity after spinal cord injury alters the severity of autonomic dysreflexia. J Neurosci 26:2923-2932.

Cao X, Shoichet MS (2003) Investigating the synergistic effect of combined neurotrophic factor concentration gradient to guide axonal growth. Neuroscience 122:381-389.

Coumans JV, Lin TT, Dai HN, MacArthur L, McAtee M, Nash C, Bregman BS (2001) Axonal regeneration and functional recovery after complete spinal cord transaction in rats by delayed treatment with transplant and neurotrophins. J Neurosci 21:9334-9344.

de Wit J, Verhaagen J (2003) Role of semaphorins in the adult nervous system. Prog Neurobiol 71:249-267.

Dickson BJ (2002) Molecular mechanisms of axon guidance. Science 298:1959-1964.

Doucet G, Petit A (2002) Seeking axon guidance molecules in the adult rat CNS. Prog Brain Res 137:453-465.

Fitzgerald M, Kwiat GC, Middleton J, Pini A (1993) Ventral spinal cord inhibition of neurite outgrowth from embryonic rat dorsal root ganglia. Development 117:1377-1384.

Fouad K, Pedersen V, Schwab ME, Brosamle C (2001) Cervical sprouting of corticospinal fibers after thoracic spinal cord injury accompanies shifts in evoked motor responses. Curr Biol 11:1766-1770.

Fu SY, Sharma K, Luo Y, Raper JA, Frank E (2000) SEMA3A regulates developing sensory projections in the chicken spinal cord. J Neurobiol $45: 227-236$

Gavazzi I (2001) Semaphorin-neuropilin-1 interactions in plasticity and regeneration of adult neurons. Cell Tissue Res 305:275-284.

Hargreaves K, Dubner R, Brown F, Flores C, Joris J (1988) A new and sensitive method for measuring thermal nociception in cutaneous hyperalgesia. Pain 32:77-88.

Hofstetter CP, Holmstrom NA, Lilja JA, Schweinhardt P, Hao J, Spenger C, Wiesenfeld-Hallin Z, Kurpad SN, Frisen J, Olson L (2005) Allodynia limits the usefulness of intraspinal neural stem cell grafts; directed differentiation improves outcome. Nat Neurosci 8:346-353.

Kim BG, Dai HN, McAtee M, Vicini S, Bregman BS (2006) Remodeling of synaptic structures in the motor cortex following spinal cord injury. Exp Neurol 198:401-415.

Kolodkin AL (1996) Semaphorins: mediators of repulsive growth cone guidance. Trends Cell Biol 6:15-22.

Lu P, Yang H, Jones LL, Filbin MT, Tuszynski MH (2004) Combinatorial therapy with neurotrophins and cAMP promotes axonal regeneration beyond sites of spinal cord injury. J Neurosci 24:6402-6409.

Messersmith EK, Leonardo ED, Shatz CJ, Tessier-Lavigne M, Goodman CS, Kolodkin AL (1995) Semaphorin III can function as a selective chemorepellent to pattern sensory projections in the spinal cord. Neuron 14:949-959.

Molliver DC, Wright DE, Leitner ML, Parsadanian AS, Doster K, Wen D, Yan Q, Snider WD (1997) IB4-binding DRG neurons switch from NGF to GDNF dependence in early postnatal life. Neuron 19:849-861.

Nakamura F, Kalb RG, Strittmatter SM (2000) Molecular basis of semaphorin-mediated axon guidance. J Neurobiol 44:219-229.
Neumann S, Doubell TP, Leslie T, Woolf CJ (1996) Inflammatory pain hypersensitivity mediated by phenotypic switch in myelinated primary sensory neurons. Nature 384:360-364.

Osterfield M, Kirschner MW, Flanagan JG (2003) Graded positional information: interpretation for both fate and guidance. Cell 113:425-428.

Ozaki S, Snider WD (1997) Initial trajectories of sensory axons toward laminar targets in the developing mouse spinal cord. J Comp Neurol 380:215-229.

Pasterkamp RJ, Giger RJ, Baker RE, Hermens WT, Verhaagen J (2000) Ectopic adenoviral vector-directed expression of Sema3A in organotypic spinal cord explants inhibits growth of primary sensory afferents. Dev Biol 220:129-141.

Pindzola RR, Doller C, Silver J (1993) Putative inhibitory extracellular matrix molecules at the dorsal root entry zone of the spinal cord during development and after root and sciatic nerve lesions. Dev Biol 156:34-48.

Priestley JV, Ramer MS, King VR, McMahon SB, Brown RA (2002) Stimulating regeneration in the damaged spinal cord. J Physiol (Paris) 96:123-133.

Puschel AW, Adams RH, Betz H (1996) The sensory innervation of the mouse spinal cord may be patterned by differential expression of and differential responsiveness to semaphorins. Mol Cell Neurosci 7:419-431.

Ramer MS, Priestley JV, McMahon SB (2000) Functional regeneration of sensory axons into the adult spinal cord. Nature 403:312-316.

Redmond L, Xie H, Ziskind-Conhaim L, Hockfield S (1997) Cues intrinsic to the spinal cord determine the pattern and timing of primary afferent growth. Dev Biol 182:205-218.

Richter MW, Fletcher PA, Liu J, Tetzlaff W, Roskams AJ (2005) Lamina propria and olfactory bulb ensheathing cells exhibit differential integration and migration and promote differential axon sprouting in the lesioned spinal cord. J Neurosci 25:10700-10711.

Romero MI, Smith GM (1998) Adenoviral gene transfer into the normal and injured spinal cord: enhanced transgene stability by combined administration of temperature-sensitive virus and transient immune blockade. Gene Ther 5:1612-1621.

Romero MI, Rangappa N, Li L, Lightfoot E, Garry MG, Smith GM (2000) Extensive sprouting of sensory afferents and hyperalgesia induced by conditional expression of nerve growth factor in the adult spinal cord. J Neurosci 20:4435-4445.

Romero MI, Rangappa N, Garry MG, Smith GM (2001) Functional regeneration of chronically injured sensory afferents into adult spinal cord after neurotrophin gene therapy. J Neurosci 21:8408-8416.

Ruitenberg MJ, Plant GW, Hamers FP, Wortel J, Blits B, Dijkhuizen PA, Gispen WH, Boer GJ, Verhaagen J (2003) Ex vivo adenoviral vectormediated neurotrophin gene transfer to olfactory ensheathing glia: effects on rubrospinal tract regeneration, lesion size, and functional recovery after implantation in the injured rat spinal cord. J Neurosci 23:7045-7058.

Sanes JR, Yamagata M (1999) Formation of lamina-specific synaptic connections. Curr Opin Neurobiol 9:79-87.

Sharma K, Frank E (1998) Sensory axons are guided by local cues in the developing dorsal spinal cord. Development 125:635-643.

Shepherd IT, Luo Y, Lefcort F, Reichardt LF, Raper JA (1997) A sensory axon repellent secreted from ventral spinal cord explants is neutralized by antibodies raised against collapsin-1. Development 124:1377-1385.

Silver J, Miller JH (2004) Regeneration beyond the glial scar. Nat Rev Neurosci 5:146-156.

Snider WD, McMahon SB (1998) Tackling pain at the source: new ideas about nociceptors. Neuron 20:629-632.

Steinmetz MP, Horn KP, Tom VJ, Miller JH, Busch SA, Nair D, Silver DJ, Silver J (2005) Chronic enhancement of the intrinsic growth capacity of sensory neurons combined with the degradation of inhibitory proteoglycans allows functional regeneration of sensory axons through the dorsal root entry zone in the mammalian spinal cord. J Neurosci 25:8066-8076.

Steward O, Zheng B, Tessier-Lavigne M (2003) False resurrections: distinguishing regenerated from spared axons in the injured central nervous system. J Comp Neurol 459:1-8.

Tanelian DL, Barry MA, Johnston SA, Le T, Smith GM (1997) Semaphorin 
III can repulse and inhibit adult sensory afferents in vivo. Nat Med 3:1398-1401.

Tang XQ, Cai J, Nelson KD, Peng XJ, Smith GM (2004a) Functional repair after dorsal root rhizotomy using nerve conduits and neurotrophic molecules. Eur J Neurosci 20:1211-1218.

Tang XQ, Tanelian DL, Smith GM (2004b) Semaphorin3A inhibits nerve growth factor-induced sprouting of nociceptive afferents in adult rat spinal cord. J Neurosci 24:819-827.

Taylor L, Jones L, Tuszynski MH, Blesch A (2006) Neurotrophin-3 gradients established by lentiviral gene delivery promote short-distance axonal bridging beyond cellular grafts in the injured spinal cord. J Neurosci 26:9713-9721.
Wright DE, Snider WD (1995) Neurotrophin receptor mRNA expression defines distinct populations of neurons in rat dorsal root ganglia. J Comp Neurol 351:329-338.

Wong ST, Atkinson BA, Weaver LC (2000) Confocal microscopic analysis reveals sprouting of primary afferent fibres in rat dorsal horn after spinal cord injury. Neurosci Lett 296:65-68.

Wujek JR, Ahmad S, Harel A, Maier KH, Roufa D, Silver J (1991) A carbohydrate polymer that effectively prevents epidural fibrosis at laminectomy sites in the rat. Exp Neurol 114:237-245.

Vulchanova L, Olson TH, StoneLS, Riedl MS, Elde R, Honda CN (2001) Cytotoxic targeting of isolectin IB4-binding sensory neurons. Neuroscience 108:143-155. 